\title{
Study of Outcome of Patients Sustaining Depressed Skull Fracture following Blunt Head Trauma
}

\author{
Bidur KC, ${ }^{1}$ Bikram Shakya, ${ }^{1}$ Amit Thapa ${ }^{1}$ \\ ${ }^{1}$ Department of Neurological Surgery, Kathmandu Medical College, Sinamangal, Kathmandu, Nepal.
}

ABSTRACT

Background: One of the common neurosurgical conditions is depressed skull fracture. It could be simple or compound type. This study aims to assess the outcome of the patients with depressed skull fracture. Material and Methods: Retrospective cohort study of the patients admitted with depressed skull fracture after sustaining blunt head trauma was done. Data were collected with regard to age, sex, mode of injury, time delay, Glasgow coma scale (GCS), epilepsy, focal neurological deficit, CT scan findings, treatment given, infection and Glasgow outcome scale (GOS). Results: Total of 50 patients were included, of which $68 \%$ were male and $32 \%$ were female with mean age of $21.02 \pm 18.78$ years. Fall was the commonest mode of injury constituting $60 \%$ of patients, $80 \%$ of the patients presented within 12 hours of injury and $86 \%$ of them sustained mild head injury. Fracture was of compound type in $56 \%$ and simple type in $44 \%$. Wound debridement and suturing was performed in $26 \%$ and Craniotomy and elevation was done in $42 \%$. Dural tear was observed in $47 \%$ who were operated. Early epilepsy was seen in $4 \%$ and late epilepsy in $2 \%$ and infection rate of $2 \%$. Outcome was Favorable in $98 \%$ patients. Significant correlation noted between admission GCS with GOS ( $\mathrm{p}=0.006$ ) whereas no correlation was seen between time of presentation with infection $(p=0.09)$.Conclusion: Mild head injury was the commonest form of presentation. Most of the patients have unfavorable outcome and with low risk of infection and epilepsy. Good admission GCS correlated with favorable outcome.

Keywords: blunt head trauma; depressed skull fracture; epilepsy; infection; outcome.

\section{INTRODUCTION}

Depressed skull fractures are one of the common neurosurgical conditions. It could be simple type with overlying Scalp intact or could be compound with overlying Scalp laceration or when fracture communicates with the paranasal sinuses or mastoid air cells. ${ }^{1}$ In Head injured patients, increased risk of intracranial lesion like hematomas and contusion, is heralded by finding a skull fracture on CT (Computed Tomography) Scan head which ultimately leading to unfavorable outcome and death. ${ }^{2-4}$

Comparing the results, a conservative and expectant management opted by 'Edwin Smith papyrus', who was a first to describe skull fractures yielded better results than the more aggressive approach according to Hippocratic literature. ${ }^{5,6}$ In 1917, when CT scan and effective antibiotics were very much scarce or unavailable, Harvey Cushing who revealed the first authentic modern details in compound depressed fracture, after his observation of patients of world war I. ${ }^{7}$ However; over the past few decades with easy availability of newer generation antibiotics and CT scan, managing the patients of compound depressed fracture has taken a major leap. ${ }^{8}$ Nevertheless, complications like infection, injury to the underlying brain, posttraumatic seizures and mortality of patients associated with compound depressed fracture are still not uncommon. ${ }^{9-11}$ Moreover, metabolic cascades as a result of severity of trauma further adds to poor outcome. ${ }^{12}$

This study aims to assess outcome of the patients with depressed skull fracture. Outcome was assessed in terms of infection, epilepsy, Glasgow outcome scale (GOS) at 6 month and correlation of admission Glasgow coma scale (GCS) with GOS at 6 month.

\section{MATERIALS AND METHODS}

This retrospective cohort study was conducted in the department of Neurological Surgery at Kathmandu Medical College Hospital (KMCH) in Sinamangal, Kathmandu, Nepal. After approval for data

Correspondence: Dr. Bidur KC, Department of Neurological Surgery, Kathmandu Medical College, Sinamangal, Kathmandu, Nepal. Email: kcbidur@gmail.com. DOI: 10.3126/jcmsn.v14i2.19913. Orcid ID: orcid.org/0000-0003-3691-8764. Article received: 2018-05-15. Article accepted: 2018-06-24. 
KC et al. Study of Outcome of Patients Sustaining Depressed Skull Fracture following..

collection from institutional review committee, data of the patients were taken, who were admitted from June 2012 to April 2015, with depressed skull fracture following blunt head trauma. Patients with large intracranial hematoma with mass effect, penetrating head trauma, bullet injury and fracture involving the base of skull were excluded.

Data were retrieved from the record files of patients or discharge summary and or operation record register, with regard to age, sex, mode of injury, time of arrival from the time of incident, GCS at presentation, early and late epilepsy, focal neurological deficit, CT scan findings, treatment given and infection. GCS was categorized into mild (GCS 13-15), moderate (GCS-9-12) and Severe $(\mathrm{GCS} \leq 8)$ head injury. Follow up was done during the out patient department (OPD) visit or from OPD record register and or by telephone contact whichever is feasible to record GOS at least 6 month post injury.GOS was dichotomized into favorable (GOS 4,5) and unfavorable (GOS 1-3). Data were entered into the excel sheet. Statistical analysis was performed using IBM SPSS Statistics version 22 (IBM Corporation, New York, USA). Data were analyzed with descriptive and inferential statistics. Fisher exact test was used for Categorical data and Spearman's rank correlation was used for correlation analysis. $\mathrm{P}$ values of $<0.05$ were considered significant.

\section{RESULTS}

There were total of 50 patients during the study period. Among them, 34 (68\%) were male and 16 (32\%) were female. Age of the patients ranged from 2 to 74 years with a mean of $21.02 \pm 18.78$ years. Fall was the commonest mode of injury found in 30 patients $(60 \%)$ followed by road traffic accidents and physical assault in 10 patients $(20 \%)$ each. Around $80 \%$ of the patients presented to hospital within 12 hours of incident, $10 \%$ within $12-24$ hours, $6 \%$ within $24-48$ hours and $4 \%$ within $48-72$ hours with mean of $12.36 \pm 15.82$ hours with minimum of 0.5 to maximum of 72 hours.GCS of 13-15 was observed in 43 patients (86\%), 9-12 in 4 patients $(8 \%)$ and 3-8 in 3 patients $(6 \%)$. Duration of hospital stay was ranged from minimum of 1 day to maximum of 85 days with mean of $8.62 \pm 11.80$ days.

Site of fracture on CT scan head were shown in Table 1. Associated findings on CT scan head was found in 32 patients (64\%) with most common being the pneumocephalus seen in 13 patients, EDH in 9 patients, contusion in 6 patients and SDH in 4 patients.

\begin{tabular}{|lc|}
\hline \multicolumn{2}{|l|}{ Table 1. Site of fracture on CT scan head. } \\
\hline Site of fracture & Number of patients (\%) \\
Parietal bone & $28(56 \%)$ \\
Frontal bone & $15(30 \%)$ \\
Temporal bone & $4(8 \%)$ \\
Occipital bone & $3(6 \%)$ \\
\hline
\end{tabular}

Evidence of Dural tear observed following craniotomy and elevation of depressed fracture in both type of fracture were noted in Table 2. Simply wound debridement and suturing was performed in 13 patients $(26 \%)$ of compound fracture type. In this study, various complications have been observed which is depicted in Table 3. Infection was observed in the form of meningitis, this patient was a case of compound depressed fracture, managed with debridement and suturing followed by intravenous antibiotics for total of 14 days.

\begin{tabular}{|lcc|}
\hline \multicolumn{3}{|l|}{ Table 2. Dural tear in both type of fracture. } \\
\hline Parameters & Simple type & Compound type \\
Type of fracture & $22(44 \%)$ & $28(56 \%)$ \\
$\begin{array}{l}\text { Craniotomy and } \\
\text { elevation }\end{array}$ & $7(14 \%)$ & $14(28 \%)$ \\
Dural tear & $3(6 \%)$ & $7(14 \%)$ \\
\hline
\end{tabular}

\begin{tabular}{|lr|}
\hline Table 3. Complications parameters. \\
\hline Variables & $\begin{array}{l}\text { Number of patients } \\
\text { (percentage) }\end{array}$ \\
Early epilepsy & $2(4 \%)$ \\
Late epilepsy & $1(2 \%)$ \\
Focal neurological deficit & $4(8 \%)$ \\
Infection & $1(2 \%)$ \\
\hline
\end{tabular}

Dichotomized GOS at 6 month was shown in Table 4. A patient who had unfavorable outcome, his presentation GCS was 4/15 and CT scan revealed compound depressed fracture and undergone craniotomy and elevation of depressed skull fracture. Significant correlation was noted between admission GCS with GOS ( $\mathrm{p}=0.006)$ whereas no statistical correlation was seen between time of presentation to hospital with incidence of infection $(\mathrm{p}=0.09)$ and simple versus compound fracture with relates to incidence of infection $(\mathrm{p}=1.00)$ and GOS $(\mathrm{p}=1.00)$.

\begin{tabular}{|lc|}
\hline \multicolumn{2}{|l|}{ Table 4. Outcome parameter. } \\
\hline GOS at 6 month & Number of patients (\%) \\
Favorable & $49(98 \%)$ \\
Unfavorable & $1(2 \%)$ \\
\hline
\end{tabular}

DISCUSSION

Over the years, many changes and improvements 
have been made for the benefit of head injured patients. One of them is Advanced Trauma Life Support (ATLS) training introduced for the first time in 1980, help the trauma patients towards the improved care. ${ }^{13,14}$ Good outcome in patients with head injury is only can be achieved by preventing and treating pathways that leads to secondary brain damage. Complications of depressed skull fractures like posttraumatic epilepsy and infection among these head injured patients are best prevented by proper prompt treatment.

There has been so much of controversy regarding the management of compound depressed fractures with different clinical conditions. ${ }^{2,15}$ compound depressed fractures are usually treated surgically to prevent intracranial infection whenever there is high probability of dural laceration. ${ }^{2,15}$ Although the surgery for these cases could provide advantages in terms of isolating the brain from external environment to decline intracranial infection, preventing entrapment by bony fragments to reduce late post-traumatic seizures and minimizing cosmetic deformity seems logical, validation of such a widespread exercise needs to be done with a newer research. ${ }^{2}$

In this study, $68 \%$ were male and $32 \%$ were female. Male preponderance was reported in various studies. ${ }^{9,16,17}$ Mean age of presentation in this study was $21.02 \pm 18.78$ years. Comparable mean age of 18.8 years mentioned by Al-Haddad et $\mathrm{a}{ }^{17}$ in his work. Fall was the commonest mode of injury found in $60 \%$ patients which is similar to a study by Ersahin et $\mathrm{al}^{18}$ who reported fall as a commonest mode of injury. This study showed GCS of $13-15$ in $86 \%$ patients. Other studies also quoted higher percentage of patients presenting with GCS of $13-15$, Mukherjee et $\mathrm{al}^{16}$ observed $66.4 \%$ and Al-Haddad et $\mathrm{al}^{17}$ reported $72 \%$. Total number of hospital stay was mean of $8.62 \pm 11.80$ days. Steinbok et $\mathrm{al}^{19}$ found mean hospital stay of 8.7 days in 36 surgically treated patients compared to 3.8 days in 28 conservatively treated group and Mukherjee et $\mathrm{a} 1{ }^{16}$ has noticed mean hospital stay of $10.3 \pm 11.7$ days of in the elevation debridement group.

This study revealed early epilepsy in $4 \%$ versus late epilepsy in $2 \%$ of the patients. Al-Haddad et $\mathrm{al}^{17}$ reported early epilepsy of $12.3 \%$ versus late epilepsy of $6.9 \%$, Jennett et $\mathrm{al}^{10}$ found early epilepsy of $10 \%$ versus late epilepsy of $15 \%$ and Mukherjee et $\mathrm{al}^{16}$ has mentioned late epilepsy of $3.7 \%$ versus $0 \%$ in simple suturing and elevation debridement group respectively. Focal deficit was observed in $8 \%$ patients in this study. In contrast, Hossain et $\mathrm{al}^{20}$ found focal deficit in $41.8 \%$ patients. Difference could be because of the differences in inclusion criteria of the study subjects.

In CT scan of head, commonest site of fracture was parietal bone followed by frontal bone in a study by Braakman $^{9}$ and Steinbok et al. ${ }^{19}$ This study also showed the same. Fracture is of compound type in $56 \%$ and simple type in $44 \%$ patients. This is in agreement with other series where compound type was commonest. ${ }^{9,18,20}$ Craniotomy and elevation of depressed fracture was done in $42 \%$ patients. Mukherjee et $\mathrm{al}^{16}$ had done surgical elevation debridement in $21 \%$ patients which is lower than this study whereas study by Braakman ${ }^{9}$ who has done surgical intervention in $73 \%$ patients and study by Hossain et $\mathrm{al}^{20}$ who has performed surgical treatment in $72 \%$ patients, which is higher than this study. Highest rate of Dural tear was seen in the compound type depressed fracture than simple type in this study, which is consistent with the study by Steinbok et al. ${ }^{19}$

In this study, we have observed infection rate of $2 \%$. Jennett et $\mathrm{al}^{21}$ has mentioned postoperative infection rate of $4.6 \%$ in patients who were not having established infection initially but with overall infection rate of $10.6 \%$. Braakman ${ }^{9}$ has reported postoperative infection of $6.6 \%$. AlHaddad et $\mathrm{al}^{17}$ has showed infection rate of $8.2 \%$. Lower incidence of infection in our study could be attributed to smaller sample size and inclusion of both simple and compound fracture.

Favorable outcome was seen in $98 \%$ of the patients in this study. In concordance with this study, Nnadi MON et $\mathrm{al}^{1}$ has highlighted good functional outcome in $88.2 \%$ and Al-Haddad et $\mathrm{al}^{17}$ has showed good outcome in $68.5 \%$ and moderate disability in $9.6 \%$ (overall favorable outcome in $78.1 \%$ ). Significant correlation was noted between admission GCS with GOS which is supported by study done by Al-Haddad et $a{ }^{17}$ who also showed lower GCS at presentation significantly associated with poor outcome $(p<0.001)$. This study didn't find statistical association between time of presentation to hospital with incidence of infection which is supported by Al-Haddad et $\mathrm{al}^{17}$ who showed no significant association between long preoperative period and infection $(\mathrm{p}=0.109)$.

Strength of this study was inclusion of simple as 
well as compound fractures patients to assess various parameters. However, there were limitations that it was a retrospective study with smaller sample size. This study can be used for future reference to conduct prospective study with inclusion of larger sample size.

\section{REFERENCES}

1. Nnadi MON, Bankole OB, Arigbabu SO.Outcome of surgically treated nonmissile traumatic depressed skull fracture.The Nigerian Postgraduate Medical Journal. 2014;21(4):311-4. PMID: 29676341

2. Bullock MR, Chesnut R, Ghajar J, Gordon D, Hartl R, Newell DW, Servadei F, Walters BC, Wilberger J. Surgical management of depressed cranial fractures. Neurosurgery. 2006;58(3):56-60. PMID:16540744

3. C. C. Hung, W. T. Chiu, L. S. Lee, L. S. Lin, and C. J. Shih. Risk factors predicting surgically significant intracranial hematomas in patients with head injuries. Journal of the Formosan Medical Association. 1996;95(4):294-7. PMID: 8935297

4. F. Servadei, G. Ciucci, F. Pagano et al., "Skull fracture as a risk factor of intracranial complications in minor head injuries: a prospective CT study in a series of 98 adult patients," Journal of Neurology Neurosurgery and Psychiatry.1988;51(4):526-8. DOI: 10.1136/jnnp.51.4.526

5. Atta HM. Edwin Smith surgical papyrus: the oldest known surgical treatise. Am Surg. 1999;65:1190-2. PMID: 10597074

6. Prioreschi P. Skull trauma in Egyptian and Hippocratic medicine. Gesnerus.1993;50:167-78. PMID: 8307390

7. Cushing H. A study of a series of wounds involving the brain and its enveloping structures. Br J Surg.1917;5:558684. https://doi.org/10.1002/bjs.1800052004

8. Dhandapani S, Sharma A, Sharma K, Das L. Comparative evaluation of MRS and SPECT in prognostication of patients with mild to moderate head injury. J Clin Neurosci. 2014;21:745-50. https://doi.org/10.1016/j.jocn.2013.07.038

9. Braakman R. Depressed skull fracture: data, treatment, and follow-up in 225 consecutive cases. J Neurol Neurosurg Psychiatry. 1972;35:395-402. http://dx.doi.org/10.1136/ jnnp.35.3.395

10. Jennett B, Miller JD, Braakman R. Epilepsy after monmissile depressed skull fracture. J Neurosurg. 1974;41:208-16. PMID: 4210275

\section{CONCLUSION}

Mild head injury was the commonest form of presentation. Most of the patients have a favorable outcome and with low risk of infection and epilepsy. Good admission GCS correlated with favorable outcome.

11. Wylen EL, Willis BK, Nanda A. Infection rate with replacement of bone fragment in compound depressed skull fractures. Surg Neurol. 1999;51:452-7. PMID: 10199302

12. Dhandapani SS, Manju D, Vivekanandhan S, Agarwal M, Mahapatra AK. Prospective longitudinal study of biochemical changes in critically ill patients with severe traumatic brain injury: factors associated and outcome at 6 months. Ind J Neurotrauma. 2010;7:23-7. DOI:10.1016/ S0973-0508(10)80007-3

13. Collicott PE, Hughes I. Training in advanced trauma life support. JAMA. 1980;243:1156-9. PMID: 7359667

14. American College of Surgeons Committee on Trauma. Advanced Trauma Life Support for Doctors, Student Course Manual. Chicago: American College of Surgeons; 1997.

15. Cooper PR. Skull fracture and traumatic cerebrospinal fluid fistulas. In: Cooper PR, editor. Head injury. 3rd edn. Baltimore: Williams and Wilkins;1993. P. 115-36.

16. Mukherjee KK, Dhandapani S, Sarda AC, Tripathi M, Salunke P, Srinivasan A et al. Prospective comparison of simple suturing and elevation debridement in compound depressed fractures with no significant mass effect. Acta Neurochir. 2015;157:305-9. PMID: 25510645

17. Al-Haddad SA, Kirollos R. A 5-year study of the outcome of surgically treateddepressed skull fractures. Ann R Coll Surg Engl.2002;84:196-200. PMID: 12092875

18. Ersahin Y, Mutluer S, Mirzai H, Palali I. Pediatric depressed skull fractures: analysis of 530 cases. Child's Nerv Syst.1996 Jun;12(6):323-31.PMID: 8816297

19. Steinbok P, Flodmark O, Martens D, Germann ET. Neurosurg. 1987;66:506-10. PMID: 3559717 Management of simple depressed skull fractures in children. J

20. Hossain M Z, Mondle M S, Hoque M M. Depressed skull fracture: outcome of surgical treatment.TAJ. 2008 Dec; 21 (2): 140-46.DOI: $10.3329 /$ taj.v21i2.3794

21. Jennett B, Miller JD. Infection after depressed fracture of skull: Implications for management of nonmissile injuries. J Neurosurg. 1972;36:333-9. PMID: 5059972

Citation: KC B, Shakya B, Thapa A. Study of Outcome of Patients Sustaining Depressed Skull Fracture following Blunt Head Trauma. 2018; 14(2):81-4. 